\title{
Stepwise diet management in pediatric gastrointestinal graft versus host disease
}

\author{
Nevra Koç ${ }^{1}$, Mehmet Gündüz' , M Fatih Azık², Betül Tavil², Dilek Gürlek-Gökçebay², \\ Eda Özaydın'1 ${ }^{1}$ Bahattin Tunç², Duygu Uçkan ${ }^{3}$ \\ ${ }^{1}$ Pediatric Nutrition and Metabolism, ${ }^{2}$ Pediatric Hematology, Department of Pediatrics, ${ }^{3}$ Hematopoietic Stem Cell \\ Transplantation Unit, Ministry of Health, Ankara Child Health and Diseases, Hematology-Oncology Training and Research \\ Hospital, Ankara, Turkey.E-mail: nevrakoc@yahoo.com \\ Received: 9 May 2016, Revised: 3 June 2016, Accepted: 11 July 2016
}

SUMMARY: Koç N, Gündüz M, Azık MF, Tavil B, Gürlek-Gökçebay D, Özaydın E, Tunç B, Uçkan D. Stepwise diet management in pediatric gastrointestinal graft versus host disease. Turk J Pediatr 2016; 58: 145-151.

Gastrointestinal tract is one of the major systems affected by graft-versus-host disease (GVHD). Injury to the gut during conditioning therapy before stem-cell transplantation (SCT) plays a pivotal role in the initiation of inflammatory stimuli. We reviewed medical records of the patients who underwent SCT between April 2010 and June 2013 in our center. A stepwise upgrade diet was given to the children with acute GI-GVHD (Gastrointestinal GVHD) including parenteral and enteral nutrition. A total of 105 patients underwent SCT and seven patients developed grade III-IV acute GI-GVHD. Total parenteral nutrition (TPN) was initiated to all patients after the diagnosis of GI-GVHD and minimal enteral nutrition $(1-2 \mathrm{ml} / \mathrm{kg} / \mathrm{day}$ standard pediatric enteral formula/special meat soup) was given to the patients. GI-GVHD improved in all patients with no change in body weight, and recovery to a normal diet took 10-30 days. Stepwise diet management of oral nutrition contributed to rapid improvement of grades III-IV acute GI-GVHD.

Key words: gastrointestinal graft versus host disease, diet management, hematopoeietic stem cell transplantation, children.

Acute graft-versus-host disease is (GVHD) is a clinicopathologic syndrome involving a severe immune reaction mediated by immunologically competent cells, mainly $\mathrm{T}$ lymphocytes resulting in organ dysfunction after stem cell transplantation (SCT) ${ }^{1}$. Gastrointestinal GVHD (GI-GVHD) is one of the most challenging complications after allogeneic SCT with the clinical symptoms of excessive diarrhea, abdominal pain and cramps, nausea, vomiting, gastrointestinal bleeding, dysphagia which can lead to malabsorption, dehydration, severe electrolyte and weight loss. Although there are no standard criteria, the diagnosis of GI-GVHD may be established by means of histological findings such as epithelial cell apoptosis with or without inflammation, epithelial sloughing and the exclusion of infectious causes ${ }^{2-4}$.

The objectives of diet management in GI-GVHD are to provide adequate nutritional support, control symptoms, heal intestinal lumen with necessary nutrients and satisfy patient preferences when possible ${ }^{5}$. However the patients with GI-GVHD often do not tolerate oral or enteral nutrition. In the acute phase with severe diarrhea ( $>1 \mathrm{~L} /$ day), nil by mouth during days to weeks is required to alleviate gastrointestinal complaints and nutritional support consisting of total parenteral nutrition (TPN). Parenteral nutrition is an integral part of supportive care for these patients but prolonged use of TPN has been associated with multiple complications including infections, fluid and electrolyte imbalances, hyperglycemia, hypertriglyceridemia and hepatic dysfunction. General recommendation is to initiate oral foods when the volume of diarrhea has decreased typically to $<500 \mathrm{ml} /$ day; however, certain foods (with low fiber, low fat) may be better tolerated than others ${ }^{6-8}$.

General guidelines of the Seattle Care Alliance recommend specific upgrade diets for patients with GI-GVHD with limited amounts of fats, fiber, lactose, acidic items and gastrointestinal 
irritants which are stepwise introduced ${ }^{9}$. Williams and Vickers ${ }^{10}$ suggested a "bland diet" for GVHD that was given by stepwise of kinds of nutrients.

In the light of the literature, we performed a stepwise upgrade diet (Table II) including five steps in the children with acute GVHD including parenteral and enteral nutrition, initiating from the first day GI GVHD was diagnosed.

\section{Material and Methods}

One hundred and five consecutive patients with a median age of 8.9 years (range $0.5-16.8$ ) were evaluated retrospectively between April 2010 and June 2013 who underwent SCT at Ankara Children's Hematology and Oncology Hospital Bone Marrow Transplantation Unit. Five patients underwent second transplantation due to relapse of the primary disease or graft rejection. All transplants were from related donors. Totally, 105 patients underwent hematopoitetic stem cell transfusion (HSCT and seven patients developed acute GI-GVHD. Patients with acute GI-GVHD received medical treatment, TPN and a stepwise upgrade diet (Fig. 1). Patient characteristics are shown in Table I.

Table I. Clinical Characteristics of the Patients

\begin{tabular}{|c|c|c|c|}
\hline & $\begin{array}{l}\text { Patients with } \\
\text { GI-GVHD }\end{array}$ & $\begin{array}{c}\text { Total } \\
\mathrm{n}\end{array}$ & $(\%)$ \\
\hline Number of the patients & 7 & 105 & 100 \\
\hline Age (years), median (range) & $5(2.5-15)$ & 8.9 & $(0.5-16.8)$ \\
\hline \multicolumn{4}{|l|}{ Gender } \\
\hline Female & 2 & 42 & 40 \\
\hline Male & 5 & 63 & 60 \\
\hline \multicolumn{4}{|l|}{ Diagnosis $(n=105)$} \\
\hline Malignancy & 3 & 49 & 46 \\
\hline Non-malignant diseases & 1 & 46 & 44 \\
\hline Congenital immunodeficiency disorders & 3 & 10 & 10 \\
\hline \multicolumn{4}{|l|}{ Type of HSCT $(n=110)$} \\
\hline Allogeneic & 7 & 99 & 90 \\
\hline Autologous & 0 & 11 & 10 \\
\hline \multicolumn{4}{|l|}{ HLA matching $(n=99)$} \\
\hline $10 / 10$ & 4 & 88 & 89 \\
\hline $9 / 10$ & 1 & 6 & 6 \\
\hline Haploidentical & 2 & 5 & 5 \\
\hline \multicolumn{4}{|l|}{ Stem cell source $(n=110)$} \\
\hline Bone marrow & 4 & 78 & 71 \\
\hline Peripheral blood & 3 & 18 & 15 \\
\hline Bone marrow and peripheral blood & 0 & 3 & 3 \\
\hline Cord blood and peripheral blood & 0 & 1 & 1 \\
\hline \multicolumn{4}{|l|}{ GVHD prophylaxis $(\mathrm{n}=99)$} \\
\hline With cyclosporine + methotrexate & 5 & 80 & 81 \\
\hline With cyclosporine only & 2 & 13 & 13 \\
\hline With cyclosporine+steroid & 0 & 6 & 6 \\
\hline \multicolumn{4}{|l|}{ Conditioning regimen $(n=110)$} \\
\hline Myeloablative & 4 & 94 & 85 \\
\hline Non-myeloablative & 3 & 16 & 15 \\
\hline
\end{tabular}

GI-GVHD: Gastrointestinal graft versus host disease 
Table II. GVHD Diets

GVHD-Step I Diet: Minimal enteral nutrition was given as special meat soup or standard pediatric entera formula (1-2 ml/kg body weight/day). The number of portions of meat soup or formula dose/frequency was increased slowly depending on gut toleration in one or two days.

GVHD-Step II Diet: One food was tested at a time. Each new food was added to the diet with foods taken previously; after consuming these foods we proceeded to step III diet. Step I diet was re-initiated in case of persisting diarrhea/cramps.

Special meat soup consisting of onion, carrot, potato, wheat flour or

Standard pediatric enteral formula

Boiled potato

Banana

GVHD-Step III Diet: The amount of portion of step II foods were increased, and one food at a time was added to other foods which had been already tolerated. After consuming these foods from the list we proceeded to step IV diet. If diarrhea/cramps persisted, step II diet was initiated.

Special meat soup consisting onion, carrot, potato, wheat flour or

Standard pediatric enteral formula

Boiled potato

Banana

White bread/toast

GVHD-Step IV Diet: Following step III foods and new foods from the list were added. After consuming all foods from the list, we proceeded to step V diet. This step included special meat soup, boiled potato, banana, white bread/toast, very low fat spagetti,

Low fat ayran

GVHD-Step V Diet: This diet included all foods in step IV diet.

Meat: Boiled meat, boiled chicken breast (no skin)

Cheese: Low fat white cheese

Soup: Yogurt soup, fermente yogurt soup (tarhana)

Fruit/Juice: Banana, stewed fruit

Fats: butter oil, olive oil

Vegetables: Well-done vegetable meal including carrots, potatot (baked, boiled), mushrooms, green beans, spinach

Bread: White bread/toast, spagetti, macaroni, corn flakes

Drinks: Weak tea, canned peach juice, low fat ayran

Enteral products: Standard/Hypercaloric pediatric enteral formula

GVHD: graft versus host disease

All patients stayed in high efficiency particulate air filtered isolation rooms. They received standard infectious prophylaxis including acyclovir (for Herpes simplex and Varicella zoster), co-trimaxazole (for P. jirovecii), metronidazole (for anaerobic infections), ciprofloxacin (for bacterial infections) and fluconazole (for Candida infections). All cellular blood products were leukocyte-depleted and irradiated prior to transfusion. All of the patients had insertion of a central venous catheter (CVC).

All of the patients received neutropenic diet before initiation of the preparative regimen to myeloid engraftment. Oral dietary intake was evaluated everyday by an experienced dietician. Before initiating the preparative regimen, each patient underwent a clinical and biological nutritional evaluation to determine weight, height, and body mass index (BMI). Dietary advice and nutritional support were adapted to attain fixed daily-recommended energy and protein requirements ${ }^{11}$. Glutamine [Resource Glutamine ${ }^{\circledR}$, Nestle, Osthofen, Germany] was given orally to all of the patients with an amount of $0.5 \mathrm{~g} / \mathrm{kg} / \mathrm{day}$. When the patients had received TPN, glutamine was added via intravenous solution [Dipeptiven ${ }^{\circledR}$ (dipeptide alanyl-glutamine), Fresenius Kabi]. Standard pediatric enteral nutrition formula is Pediasure ${ }^{\circledR}$ (Abbott, Zwolle, Holland), ( $1 \mathrm{kcal} / \mathrm{ml}, 44.4 \%$ carbohydrate, $11.1 \%$ protein, $44.5 \%$ fat, osmolarity $273 \mathrm{mosm} / \mathrm{L}$ ), hypercaloric pediatric enteral formula is Pediasure plus ${ }^{\circledR}$ (Abbott, Zwolle, Holland), $(1.5 \mathrm{kcal} / \mathrm{ml}, 44.4 \%$ carbohydrate, $11.1 \%$ protein, $44.5 \%$ fat, osmolarity $390 \mathrm{mosm} / \mathrm{L}$ ), infantile enteral formula is Similac high energy ${ }^{\circledR}$ (Abbott, Zwolle, Holland), (1 kcal/ $\mathrm{ml}, 40.3 \%$ carbohydrate, $10.4 \%$ protein, $48.5 \%$ fat, osmolarity $284 \mathrm{mosm} / \mathrm{L}$ ) and standard pediatric tube feeding formula is Nutrini ${ }^{\circledR}$ (Nutricia, Zoetermeer, Holland) (1 kcal/1ml, 
$\mathrm{n}=\mathbf{1 0 5}$ (median age $=8.9$ ) underwent HSCT $\mathrm{n}=7$ developed acute $\mathrm{GI}-\mathrm{GVHD}$

Acute GI-GVHD Medical Therapy

Acute GI-GVHD Diet Therapy

1. TPN and Minimal enteral nutrition

2. Stepwise upgrade Diet

Fig. 1. Study design

aroma free, $50 \%$ carbohydrate, $10 \%$ protein, $40 \%$ fat, osmolarity $200 \mathrm{mosm} / \mathrm{L}$ ).

Graft-versus-host disease prophylaxis consisted of cyclosporine (CSA) (1-3 mg/kg/day i.v.) and a short course of methotrexate (MTX) $(15 \mathrm{mg} /$ $\mathrm{m}^{2}$ on day +1 and $10 \mathrm{mg} / \mathrm{m}^{2}$ on days +3 and $+6)$ in the majority of patients. Acute GVHD was diagnosed on the basis of clinical symptoms and according to evaluation of gut biopsies in all 7 patients $^{12}$. Acute GI-GVHD was graded from 0 (absent) to IV according to previously published criteria according to Glucksberg et al. ${ }^{13}$. Patients with diarrhea $10-19.9 \mathrm{ml} / \mathrm{kg} /$ day were scored as grade I GI-GVHD, patients with diarrhea $20-30 \mathrm{ml} / \mathrm{kg} /$ day were scored as grade II GI-GVHD, patients with diarrhea $>30 \mathrm{ml} / \mathrm{kg} /$ day were scored as grade III GI-
GVHD, and patients with severe abdominal pain, with or without ileus were scored as grade IV GI-GVHD. Patients with diarrhea had stool analysis negative for virus, bacteria, fungi, and protozoa. Total PN was initiated to all patients after the diagnosis of GI-GVHD and also minimal enteral nutrition $(1-2 \mathrm{ml} / \mathrm{kg} /$ day standard pediatric enteral formula/special meat soup) was given to the patients to prevent development of intestinal atrophy ${ }^{14}$. TPN was infused via a CVC overnight, for a minimal duration of 12 hours. TPN administration was stopped when oral dietary intake approached energy and protein requirements. A modified diet protocol including five steps was used (Table II). This diet is modified from the basis on Williams and Vickers ${ }^{10}$ which suggested a "bland diet" for GVHD that was given by stepwise of kinds of nutrients.

\section{Results}

In the Bone Marrow Transplantation Unit, 105 patients underwent HSCT seven patients developed acute GI-GVHD ( 5 of them grade III and 2 of them grade IV). Clinical characteristics of the patients with acute GI-GVHD were presented in Table III. TPN was given to all

Table III. Clinical Characteristics of the Patients with Acute GI-GVHD

\begin{tabular}{cccccccc}
\hline NO & $\begin{array}{c}\text { Age } \\
\text { (years) }\end{array}$ & Gender & $\begin{array}{c}\text { Height } \\
(\mathrm{cm})\end{array}$ & $\begin{array}{c}\text { Weight } \\
(\mathrm{kg})\end{array}$ & $\begin{array}{c}\text { Underlying } \\
\text { disease }\end{array}$ & $\begin{array}{c}\text { Type of SCT } \\
\text { HLA matching }\end{array}$ & GVHD Grade \\
\hline 1 & 15 & M & 165 & 42 & ALL, relapsed & $\begin{array}{c}\text { Allogeneic, sibling, } \\
10 / 10\end{array}$ & IV (Day 30) \\
2 & 5 & M & 115 & 25 & $\begin{array}{c}\text { Congenial } \\
\text { eryhropoietic } \\
\text { porphria } \\
\text { Chediak- } \\
\text { Higashi } \\
\text { syndrome } \\
\text { SCID }\end{array}$ & $\begin{array}{c}\text { Allogeneic, sibling, } \\
6 / 6\end{array}$ & III (Day 38) \\
4 & 2.5 & M & 87 & 10.8 & $\begin{array}{c}\text { Allogeneic, sibling, } \\
10 / 10\end{array}$ & III (Day 37) \\
father, 4/6 & IV (Day 96) \\
5 & 5 & F & 76 & 8 & $\begin{array}{c}\text { Allogeneic, father, } \\
8 / 10\end{array}$ & III (Day 98) \\
6 & 5 & M & 111 & 21,5 & FHL & $\begin{array}{c}\text { Allogeneic, sibling, } \\
9 / 10\end{array}$ & III (Day 36) \\
7 & 10 & M & 137 & 21 & AML, relapsed & $\begin{array}{c}\text { Allogeneic, sibling, } \\
10 / 10\end{array}$ & III (Day 40)
\end{tabular}

ALL: acute lymphoblastic leukemia; AML: acute myelogenous leukemia; FHL: familial hemophagocytic lymphohistiocytosis; SCID: severe combined immunodeficiency disease $\mathrm{M}$ : male, $\mathrm{F}$ female GI-GVHD: gastrointestinal graft versus host disease HLA: Human Leucocyte Antigen, SCT: Stem cell Transplantation 


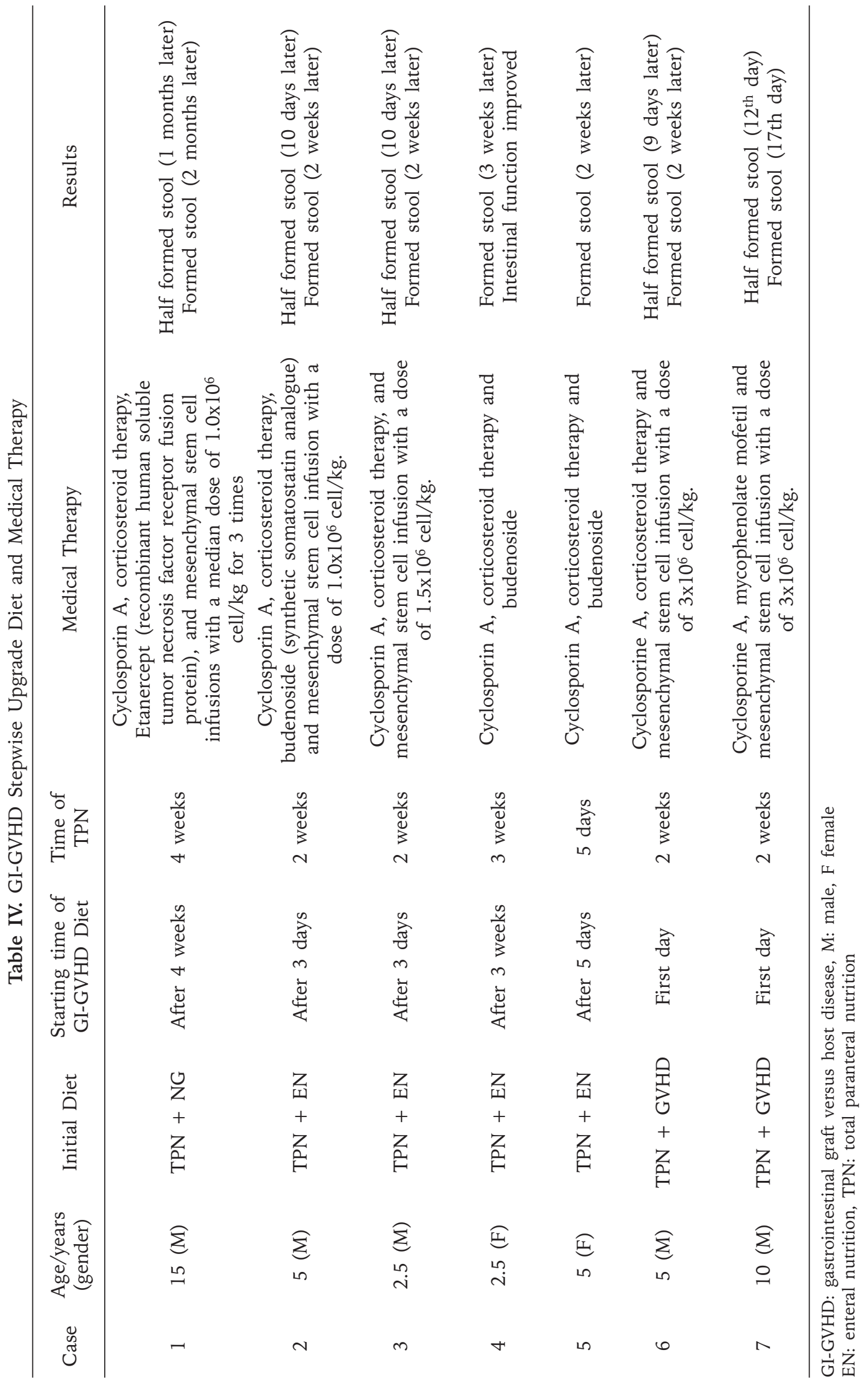


the patients for a median period of 14.5 (range 5-30) days. Oral nutrition was initiated from the first day of the protocol except for Case 1 who was unable to eat from the first day. Glutamine was given to all patients with an amount of $0.5 \mathrm{~g} / \mathrm{kg} /$ day. As expected, period of TPN use was longer in patients with GVHD grade IV when compared to those with GVHD grade III (Grade IV: 21- 30 day, Grade III: 1014 day). The diet management and medical therapy of the patients with acute GI-GVHD were presented in Table IV.

\section{Discussion}

The gastrointestinal (GI) tract is one of the major organs affected by GVHD. Injury to the gut during conditioning therapy before SCT plays a pivotal role in the initiation of increasing the translocation of inflammatory stimuli such as endotoxin, which promotes further inflammation and additional GI tract damage. The GI tract is critical to the initiation of the 'cytokine storm' characteristic of acute GVHD'5. With the development of acute GVHD, patients are often recommended to withhold oral intake (NPO: Nil Per Os, 'bowel rest') to avoid further damage to the GI mucosa. However, this raises a serious concern since NPO care can induce atrophy of the GI mucosa and cause dysfunction of the GI system ${ }^{5}$. Recent preliminary findings suggest that early enteral feeding following SCT is associated with low ratio GVHD and lower infection mortality at 100 days post transplant ${ }^{16,}{ }^{17}$. In this study; we evaluated the dietary intake patterns of seven children who underwent HSCT and developed GVHD. TPN was initiated to all the patients after the diagnosis of GI-GVHD and simultaneously, minimal enteral trophic nutrition was added to TPN for all patients; thus none of the patients were given a NPO.

Enteral nutrition is generally recommended to maintain digestive and absorptive function as early as possible. Oral intake after HSCT may influence the development of acute GVHD after SCT. Mattsson et $\mathrm{al}^{15}$. studied the nutritional history in 231 patients after allogeneic SCT and they found time to-unable-to-oral intake was associated with risk of grades III-IV acute GI-GVHD which was reached at $10 \%$. Otherwise, in our study, rate of grades III-IV acute GI-GVHD was $6 \%$. Oral dietary intake of the patients was evaluated everyday by an experienced dietician, and enteral nutritional support was started as needed. TPN was initiated to all patients after the diagnosis of grades III-IV acute GI-GVHD, and also minimal enteral nutrition was given.

Children who are undergoing bone morrow transplantasyon (BMT), who have GVHD, or who may have inadequate intestinal nutrient absorption postchemotherapy may require TPN. In patients receiving SCT, high dose chemotherapy regimens and total body irradiation can damage the gastrointestinal tract and cause mucositis and enteritis, resulting in difficulty in taking an oral or enteral diet ${ }^{18}$. In acute phase with severe diarrhea $(>1 \mathrm{~L} /$ day), nil by mouth during days to weeks (or even months) is required to alleviate gastrointestinal complaints, and nutritional support consist of TPN. When the volume of diarrhea decreases (typically to $<500 \mathrm{ml} /$ day) oral food is restarted, but certain foods (with low fiber and fats) may be better tolerated than others ${ }^{6-8}$. The common approach in nutritional management of GI-GVHD has been administration of TPN and initiation of oral intake upon recovery of abdominal complaints which may take long time. General guidelines of the Seattle Cancer Care Alliance recommend spesific upgrade diets for patients with GIGVHD, with limited amounts of fats, fiber, lactose, acidic items and GI irritants which are stepwise introduced. This diet is modified from the basis on Williams and Vickers ${ }^{10}$ which suggested a "bland diet" for GVHD that was given by stepwise of kinds of nutrients. The list of nutrients used in the patients presented here was prepared considering the major differences in dietary choices according to cultural differences. Foods that caused diarrhea and crampy abdominal pain were excluded, and steps were diversified and more controlled. It is important to add new foods to patients' diet more slowly than they regularly would.

Imataki et al. ${ }^{9}$ investigated effects of this stepwise upgrade diet in 18 patients with GI-GVHD. In that prospective study, the stepwise upgrade diet was compared with a group of historical control patients receiving nil by mouth and TPN alone. Changes in body weight were not significantly different between groups. The oral diet appeared to be safe for the patients suffering from GI-GVHD and recovery to a normal diet tended to be 
shorter ( 31 vs. 38 days, $\mathrm{p}=0.09$ ) in the stepwise upgrade diet group. The patients presented here received minimal enteral nutrition with TPN initiating from the first day of GI-GVHD. Intestinal GVHD improved in all patients with no change in body weight, and recovery to a normal diet lasted for 10-30 days which were given in the results.

L-glutamine was given to all patients presented here with an amount of 0.3$0.5 \mathrm{~g} / \mathrm{kg} /$ day. When the patients received TPN, glutamine was added via intravenous dipeptiven ${ }^{\circledR}$ solution. In experimental and clinical studies, supplementation of glutamine has been demonstrated to restore the integrity of the GI mucosa and decreased bacterial translocation during cancer treatment. The nonessential amino acid glutamine is precursor for nucleotide synthesis; rapidly dividing cells, such as enterocytes, are most likely to suffer from a shortage of glutamine. During stress and trauma endogenous production of glutamine may become insufficient while consumption of glutamine by lymphocytes and enterocytes is increased. Glutamine not only modulates the immune system function in the digestive tract, but may also promote intestinal healing and reduce the severity of mucositis and GVHD. Cochrane review concluded that oral glutamine may reduce mucositis, days of opioids and risk of $\mathrm{GVHD}^{2}$.

In conclusion, according to our observation in a small group of patients with grade III-IV GI GVHD, it may be stated that early initiated advanced nutritional support and stepwise diet management provides rapid improvement in digestive tract and may accelerate recovery period in children with grades III-IV acute GI GVHD.

\section{REFERENCES}

1. Ferrara JL, Levine JE, Reddy P, Holler E. Graft-versushost disease. Lancet 2009; 373: 1550-1061.

2. Van Der Meij BS, De Graaf P, Wierdsma NJ, et al. Nutritional support in patients with GVHD of the digestive tract: state of the art. Bone Marrow Transplant 2013; 48: 474-482.

3. Akpek G, Chinratanalab W, Lee LA, et al. Gastrointestinal involvement in chronic graft-versus-host disease: a clinicopathologic study. Biol Blood Marrow Transplant 2003; 9: 46-51.

4. Filipovich AH, Weisdorf D, Pavletic S, et al. National Institutes of Health consensus development project on criteria for clinical trials in chronic graft-versus-host disease: I. Diagnosis and staging working group report. Biol Blood Marrow Transplant 2005; 11: 945-956.

5. Akbulut G. Gastro-intestinal graft-versus-host disease: A guide for recent dietary therapy: Review. Turkiye Klinikleri J Gastroenterohepatol 2011; 18: 29-37.

6. Flowers ME, Mcdonald G, Carpenter P, et al. Longterm follow-up after hematopoietic stem cell transplant general guidelines for referring physicians. Fred Hutchinson Cancer Research Center/Seattle Cancer Care Alliance, Version 4 August 2008: 1-78.

7. Rzepecki P, Barzal J, Oborska S. Blood and marrow transplantation and nutritional support. Support Care Cancer 2010; 18 (Suppl 2): 57-65.

8. Martin-Salces M, De Paz R, Canales MA, Mesejo A, Hernandez-Navarro F. Nutritional recommendations in hematopoietic stem cell transplantation. Nutrition 2008; 24: 769-775.

9. Imataki O, Nakatani $\mathrm{S}$, Hasegawa $\mathrm{T}$, et al. Nutritional support for patients suffering from intestinal graftversus-host disease after allogeneic hematopoietic stem cell transplantation. Am J Hematol 2006; 81: 747-752.

10. Williams DB, Vickers CR. Gastrointestinal complications. In: Kerry Atkinson (ed). Clinical Bone Marrow ND Blood Stem Cell Transplantation (2 ${ }^{\text {nd }}$ ed), Vol. 69. USA: Cambridge University Press; 2000: 903-909.

11. Merdol TK. The Ministry of Health of Turkey, General Directorate of Primary Health Care, FoodSafety Department Community Nutrition Division. Dietary Guidelines for Turkey. Ankara: Onur Publishing; 2006: 57-65.

12. Cruz-Correa M, Poonawala A, Abraham SC, et al Endoscopic findings predict the histologic diagnosis in gastrointestinal graft-versus-host disease. Endoscopy 2002, 34: 808-813.

13. Glucksberg H, Storb R, Fefer A, et al. Clinical manifestations of graft-versus-host disease in human recipients of marrow from HL-A-matched sibling donors. Transplantation 1974; 18: 295-304.

14. Guieze R, Lemal R, Cabrespine A, et al. Enteral versus parenteral nutrition support in allogeneic haematopoietic stem-cell transplantation. Clin Nutr 2014; 33: 533-538.

15. Mattsson J, Westin S, Edlund S, Remberger M. Poor oral nutrition after allogeneic stem cell transplantation correlates significantly with severe graft-versus-host disease. Bone Marrow Transplant 2006; 38: 629-633.

16. Lenssen P, Aker S. Nutrition Support of the Hematopoietic Cell Transplant Recipient. In: Frederick R. Appelbaum, Stephen J. Forman, Robert S. Negrin, Karl G. Blume (ed). Thomas' Hematopoietic Cell Transplantation: Stem Cell Transplantation (4th ed), Vol. 101. USA: Blackwell Publishing; 2009: 1551-1569.

17. Seguy D, Berthon C, Micol JB, et al. Enteral feeding and early outcomes of patients undergoing allogeneic stem cell transplantation following myeloablative conditioning. Transplantation 2006; 82: 835-839.

18. Svahn BM, Remberger M, Heijbel M, et al. Case-control comparison of at-home and hospital care for allogeneic hematopoietic stem-cell transplantation: the role of oral nutrition. Transplantation 2008; 85: 1000-1007. 